$\xi=$

\title{
Effect of risk factors of bronchial asthma on elderly health related quality of life at assiut university hospital, Egypt
}

\author{
Nermeen Mahmoud Abd Elaziz Barakat* \\ Lecturer of Gerontological Nursing Department, Faculty of Nursing, Assiut University, Egypt \\ *Corresponding author E-mail: nermeenbarakat@aun.edu.eg
}

\begin{abstract}
The present study aimed to assess quality of life of elderly asthmatics and to determine risk factors that may influence it. The study was carried out in the chest out-patient clinics and chest departments at Assiut University Hospital. The sample type of this study total coverage during one year consists of one hundred and five elderly people aged 60 years and above suffering from bronchial asthma disease. Two tools were used for data collection, tool one divided into three parts, socio-demographic data risk factors assessment, and history of bronchial asthma. Tool two to assessment health related quality of life of asthmatic patients was using St. George's Respiratory Questionnaire (SGRQ). The main results yielded by the study proved that, there were highly significant differences between risk factors of bronchial asthma disease and health-related quality of life. The study recommended that further research be implemented to improve the effect of health related quality of life for asthmatic patients.
\end{abstract}

Keywords: Elderly; Bronchial Asthma; Risk Factors; Quality of Life.

\section{Introduction}

Elderly has been defined as a chronological age of 65 years old or older, while those from 65 through 74 years old are referred to as "early elderly" and those over 75 years old as "late elderly." Quality of life (QOL) conveys an overall sense of well-being, including the ability to attempt to assess aspects of happiness and satisfaction with life as a whole (Geriatrics \& Gerontology International, 2006).

Asthma is a significant chronic problem in the elderly. Asthma in the elderly is an important public health problem. There is a need to pay more attention to this disease in patients over 60 years old to prevent the worse quality of life. Asthma severity impacts on these participants' QOL and health status. Increased asthma severity was associated with significantly lower QOL and a trend toward decreased health status (Chinn, 2006).

Asthma is defined as an inflammatory disorder characterized by variable airflow obstruction, airway hyper responsiveness to specific and nonspecific stimuli; and symptoms of wheezing, chest tightness, cough and dyspnea. Heightened airway responsiveness is a pathognomonic feature of asthma (Pascual, 2008).

Factors that can affect asthma control and self-management in people aged 65 years and over include co-morbidity, chest infections, cognitive decline, social isolation, anxiety and depression, long-term smoking, for the major allergens of house dust, obesity, dysfunctional breathing and exercise limitation (Gibson, 2010).

Asthma in the elderly patients adversely affects quality of life and results in a higher hospitalization rate and mortality. But the disease is under-diagnosed and under treated in them. The high incidence of co-morbid conditions makes the diagnosis and management more difficult. Despite the availability of effective antiasthma drugs, many old patients with asthma remain uncontrolled. Careful attention should be paid to the adherence to therapy, particularly in patients with co-morbidities (Debajyoti et al., 2011).
Nurses play an important role in caring with asthmatics patients' to manage their disease process independently. Nurse should provide all routine preventive care as vaccinations recommended for asthmatics elderly patient and medication of asthma. Additionally, pulmonary infections that increased risk for recurrent of asthma and complications (e.g., hospitalization, increased use of antibiotics). Influenza vaccination is performed annually for all patients with asthma (Joyce et al., 2010).

\subsection{Significant of the study}

Asthma is a disease with increasing global significance. It is estimated that by the year 2025 , the prevalence will have risen from the current 300 million to 400 million worldwide (Braman, 2006). Asthma is a chronic condition affecting millions of individuals worldwide and has a substantial incidence rate that continues to rise (Ford, 2005).

However, there are very few studies on Quality of Life in elderly asthmatics, there is evidence to suggest that asthma is more severe in the elderly since, in this age group, co-morbidities are more prevalent and there is a lower control of the disease, thereby having a greater negative impact on general well-being and QOL, when compared with younger patients (Quadrelli, et al., 2011).

\subsection{Aim of the study}

To assess quality of life of elderly asthmatics and to determine risk factors that may influence it.

\subsection{Research hypothesis}

Quality of Life in elderly asthmatics seems to be lower than that in younger asthmatics, due to a lower degree of disease control and the presence of co-morbidities. 


\section{Subjects and methods}

\subsection{Research design}

Descriptive cross-sectional research design was used in this study.

\subsection{Setting}

This study was carried out in two different settings as follows:-

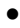

Chest out-patient clinics (males and females) of Assiut University Hospital. This clinic provides health care services to chest diseases patients for surrounding rural and urban areas at Assiut Governorate.

General emergency unit in Assiut University Hospital. This unit provides emergency services for all patients especially chest diseases patients.

Chest departments or in-patient chest wards (males and females) in Assiut University Hospital.

\subsection{Subjects or sample}

The sample type of this study total coverage during one year consists of (105) elderly patients suffering from bronchial asthma disease. They agreed to participate in the study and ability to communicate without any mental or psychiatric disorder, which were recruited from the previously mentioned settings.

\subsection{Tools}

A structured interview sheet was developed by the researcher based on relevant literature in order to assess the quality of life and risk factors among asthmatic elderly patients. It consisted of two tools.

Tool 1:- This tool divided into three parts.

Part I: This part designed by the researchers to gather information related to patient's socio-demographic data such as age, gender, and marital status, level of education, occupation and smoking history.

Part II: This part it includes items related to the risk factors and surrounding environmental areas such as the housing near from malefactor areas, exposure to sun lights, present kitchen, present original heater, exposure to pollutions, and the types of floors.

Part III: This part included items related to history of bronchial asthma disease as:-

1) Present history of bronchial asthma disease: included chief complains: such as coughing, dyspnea and wheezing in the chest. Onset of disease: it includes date of starting disease, duration of disease and measures taking. Allergies: from foods, odors, season, others and sleep disturbance.

2) Present history of medical diseases: include chronic illness (present or not) if present history of medical disease (positive), what the name of this disease, such as diabetes mellitus, hypertension, liver diseases, heart diseases, kidney diseases and other diseases.

3) Past history of bronchial asthma disease: it includes questions about previous history of this disease (yes or no), if yes what the frequency as once, twice, tripled or more. Also, questions about previous history of allergic diseases such as skin, eyes, nose, and others diseases. And previous history of admission to hospital, emergency and intensive care units by the asthma if (admitted), what the frequency as once, twice, tripled or more.

4) Family history of bronchial asthma disease: it includes questions about previous family history of this disease (yes or no), if yes what the relation such as son, daughter, wife, husband and others. Questions about previous family history of another allergic diseases (yes or no) if yes, what the type of this diseases such as skin, eyes, nose, and others diseases. Question about present family member smoker (yes or no) if yes, what the relation to affected elderly patient such as father, son, brother, husband and others (Appendix I).

Tool 2: Quality of life assessment sheet:

The original scale, to assessment health related quality of life (QOL) of asthmatic patients was done by using Arabic version of St.George's Respiratory Questionnaire (SGRQ) that was developed by Stein et al., 2004. This scale standardized air way disease specific divided into four subscale symptoms score, activity, impacts and total scores. Symptoms score: (Questions 1-7) addresses the frequency of respiratory symptoms to assess the patient's perception of their recent respiratory problems. Activity score: (Questions 8-14) addresses the patient's current state (i.e. how they are these days). The Activity score measures disturbances to daily physical activity. The Impacts score covers a range of disturbances of psycho-social function, also correlates quite strongly with exercise performance (6-minute walking test), breathlessness in daily life and disturbances of mood (anxiety and depression). Impacts score is covering the whole range of disturbances that respiratory patients experience in their lives and total score is covering the impact of the disease on overall health status.

Scoring System: The total score is calculated by summing the weights to all the positive responses in each component. The score for each component is calculated separately by dividing the summed weights by the maximum possible weight for that component and expressing the result as a percentage: The Total score is calculated in similar way:

Score $=100 \mathrm{x}$ Summed weights from all positive items in the questionnaire

Sum of weights for all items in the questionnaire

1) Calculate the mean and SD of each item (Symptoms score, activity score, impacts score and total score )

2) If patient less than mean $+\mathrm{SD}$ considered good

3) If patient between mean $+\mathrm{SD}$ and mean $+\mathrm{SD}$ considered moderate

4) If patient more than mean $+\mathrm{SD}$ considered poor

5) This tool was adopted from (Stein et al., 2004) and translated into Arabic language then retranslated into English to assure its accuracy.

Validity and reliability:

Content validity was ascertained by a group of five experts in chest department at Assuit University hospital. Their opinions were elicited regarding to the tools format layout, consistency and scoring system. Contents of the tools were tested regarding to the knowledge accuracy, relevance and competence. Testing reliability of tools items was done using alpha cronbach test: tool I = 0.94 , tool II $=0.84$, tool III $=0.93$, and, tool $\mathrm{V}=0.92$.

\subsection{Methods}

- $\quad$ An official permission was obtained from the directors of setting at Assiut University hospital to obtain his vital assistance and necessary approval to conduct the study. These letters included a permission to carry out the study in the previously mentioned settings. The nature and purpose of the study were briefly explained through direct personal communication.

Elderly patients' verbal agreement for participation was obtained after explanation of the purpose of the study.

The tools were developed based on a review of relevant literature which was translated into Arabic language by the researcher.

A pilot study was conducted to evaluate the validity and reliability of the questionnaire. It was carried out on a sample of 10 elderly patients suffering from bronchial asthma disease drawn from the previous settings. These 10 patients were excluded from the actual sample. Also the pilot study was done to evaluate the applicability and clarity of the tool. Accordingly, the necessary modifications were done.

Regarding the collection of data the researcher interviewed the elderly patients on an individual basis. The researcher introduced the sheet to the elderly patients and 
asked them to complete it after explaining the purpose of the study to them. The researcher completed the sheet for illiterate patients and wrote exactly the answers that the elderly patients gave. The approximate time spent during the interview was half an hour.

Collection of data was done for one year (from March 2013 to February 2014).

"Brochure" prepared and designs by the researcher with Arabic languish it was gave to each studied patient which contain the meaning of the asthma, what are the causes and risk factors also contain what are irritants of asthma and how to prevent it.

\subsection{Ethical consideration}

Ethical approval was obtained from the Scientific Research Ethical Committee of Assiut University and written informed consent was obtained from each participant. In addition, they were assured that anonymity and confidentiality would be guaranteed and their right to withdraw from the study at any time without any reason.

\subsection{Statistical analysis}

The obtained data were reviewed, prepared for computer processing, coded, analyzed and tabulated. Data entry was done using the Epi-info 6.4 computer software package, while statistical analysis was done using the SPSS 16.0 statistical software package. Data was presented using descriptive statistics in the form of frequencies and percentages, means, standard deviations and using chi-square test. Statistical significance was considered at P-value $<0.05$.

\section{Results}

Table (1) illustrates the distribution of the study sample regarding their socio-demographic characteristics. As regards the age ranged between $(65-80)$ years, the mean age \pm S.D was $(65.6+4.1)$. More than half of them $(51.4 \%)$ were males, while the most of them $(85.7 \%)$ from rural areas and $(62.9 \%)$ of them were widows. Regarding the educational status, it was observed that the majority of the study sample $(88.6 \%)$ were illiterate, while $1.9 \%$ of them wear farmers, also about two third of them $(70.5 \%)$ had in come $60<120$ pounds, and more than half $(58.1 \%)$ of them were living alone.

Table (2) illustrates that $100 \%$ of participants had coughing and dyspnea. As regards type of medication it was observed that $98.1 \%$ of them taking bronchodilator, $42.9 \%$ of them had duration of asthma about few weeks and more than two third $71.4 \%$ of them had more than twice frequency of wakening.

Table (3) illustrates that more than half of participants $55.6 \%$ had twice frequency of occurred severe asthma, $53.3 \%$ of them complain of severity of asthma at end of night and majority of patients choose winter season. As regards type of chronic diseases it was observed that $34 \%$ of studied sample had hypertension and the vast majority $96.2 \%$ of them had smoker in the family.

Table (4) show that $100 \%$ of studied sample agree that asthma caused by common cold, exposed to dust, exposed to smoking, exposure to dust, increased with cold weather and anxiety. While $92.4 \%$ of them not exposure to pollutions and $77.1 \%$ of elderly patients do not dressing specific clothes is a risk factor to asthma.

Table (5) show that activity score range $86.5-100$ with Mean + SD $95.2+5.1$, while total score range 77.1 - 95.3 with mean + SD $89.3+4.9$.

Table (6) show that statistical significant difference between time of severity and total score range $\mathrm{P}$-value $0.00^{*}$, also there is statistical significant difference between symptoms score and season of severity P-value 0.021 *

Also table show that there is no statistical significant difference between exposed to heavy effort and total score P-value 0.299, while there is statistical significant difference between smell specific odor and total score P-value $0.000 *$.

Table 1: Distribution of the Study Sample Regarding Socio-Demographic Characteristics at Assiut University Hospital.

\begin{tabular}{|c|c|c|c|}
\hline \multirow{2}{*}{\multicolumn{2}{|c|}{ Socio-demographic characteristics }} & \multicolumn{2}{|c|}{$($ No. $=105)$} \\
\hline & & No. & $\%$ \\
\hline \multicolumn{2}{|c|}{ Age (years): } & \multirow{3}{*}{\multicolumn{2}{|c|}{$\begin{array}{l}65-80 \\
65.6 \pm 4.1\end{array}$}} \\
\hline & Range & & \\
\hline • & Mean \pm S.D & & \\
\hline \multicolumn{4}{|c|}{ Sex: } \\
\hline$\bullet$ & Male & 54 & 51.4 \\
\hline$\bullet$ & Female & 51 & 48.6 \\
\hline \multicolumn{4}{|c|}{ Resident: } \\
\hline$\bullet$ & Rural & 90 & 85.7 \\
\hline$\bullet$ & Urban & 15 & 14.3 \\
\hline \multicolumn{4}{|c|}{ Marital status: } \\
\hline$\bullet$ & Married & 39 & 37.1 \\
\hline$\bullet$ & Widow & 66 & 62.9 \\
\hline \multicolumn{4}{|c|}{ Educational status: } \\
\hline$\bullet$ & Illiterate & 93 & 88.6 \\
\hline$\bullet$ & Read\& write & 12 & 11.4 \\
\hline \multicolumn{4}{|c|}{ Occupation: } \\
\hline$\bullet$ & Farmer & 2 & 1.9 \\
\hline$\bullet$ & House wife & 51 & 48.6 \\
\hline$\bullet$ & Retired & 38 & 36.2 \\
\hline$\bullet$ & Technical\& non-technical & 14 & 13.3 \\
\hline \multicolumn{4}{|c|}{ Monthly income (pound): } \\
\hline$\bullet$ & $60-$ & 74 & 70.5 \\
\hline$\bullet$ & $120-$ & 12 & 11.4 \\
\hline$\bullet$ & $240+$ & 19 & 18.1 \\
\hline \multicolumn{4}{|c|}{ Family size: } \\
\hline$\bullet$ & Living alone & 61 & 58.1 \\
\hline$\bullet$ & $3-4$ & 21 & 20.0 \\
\hline$\bullet$ & $5-6$ & 11 & 10.5 \\
\hline$\bullet$ & 7or more & 12 & 11.4 \\
\hline
\end{tabular}

Table 2: Distribution of the Study Sample Regarding Their Present History $(\mathrm{N}=105)$

\begin{tabular}{lll}
\hline Present history & $\mathrm{N}$. & $\%$ \\
\hline Signs \& Symptoms \# & 105 & 100.0 \\
- Coughing & 105 & 100.0 \\
- Dyspnea & 56 & 53.3 \\
- Wheezing & & \\
Discovery age of disease & 58 & 55.2 \\
- 40 - <50 years & 27 & 25.7 \\
- 50 - <60 years & 20 & 19.0 \\
- 60+ years & & \\
Discovery place of disease & 74 & 70.5 \\
- Privet clinic & 31 & 29.5 \\
- General hospital & & \\
Frequency of attending to chest clinic & 4 & 3.8 \\
- Not present & 72 & 68.6 \\
- Once every month & 11 & 10.5 \\
- Once every six months & 18 & 17.1 \\
- Once every year & & \\
Type of medication\# & 103 & 98.1 \\
- Bronchodilator & 102 & 97.1 \\
- Cortisone & 82 & 78.1 \\
- Anti-coughing & 31 & 29.5 \\
- Anti-allergy & & \\
Duration of asthma & 4 & 3.8 \\
- Few minutes & 36 & 34.3 \\
- Few hours & 20 & 19.0 \\
- Few days & 45 & 42.9 \\
- Few weeks & 40 & 38.1 \\
What do you doing with asthma & 65 & 61.9 \\
- Know & & \\
- I don't Know & 35 & 28.6 \\
Frequency of wakening & & 71.4 \\
- Twice & & \\
- More than twice & & \\
Source of information & & \\
- Doctor & & \\
- Nurse & & \\
- Relative & & \\
\hline - More than one answer & & \\
\hline
\end{tabular}

\# More than one answer 
Table 3: Distribution of the Study Sample Regarding Their Past History and Family History $(\mathrm{N}=105)$

\begin{tabular}{lll}
\hline Past history & N. & $\%$ \\
\hline Frequency of hospital admitted in the last year & & \\
- Once & 31 & 29.5 \\
- Twice & 55 & 52.4 \\
- More than twice & 4 & 3.8 \\
- Not admitted & 15 & 14.3 \\
Frequency of occurred severe asthma & & \\
- Once & 16 & 17.8 \\
- Twice & 50 & 55.6 \\
- More than twice & 24 & 26.7 \\
Frequency of admitted on emergency unit & & \\
- Once & 37 & 53.6 \\
- Twice & 32 & 46.4 \\
Duration of admitted on intensive care unit & & \\
- Few weeks & 28 & 53.8 \\
- Few months & 24 & 46.2 \\
Time of severity & & \\
- Early morning & 33 & 31.5 \\
- At evening & 16 & 15.2 \\
- At end of night & 56 & 53.3 \\
Season of severity & & \\
- Winter & 87 & 82.9 \\
- Spring & 18 & 17.1 \\
Place of severity & & \\
- At home & 50 & 47.6 \\
- At street & 55 & 52.4 \\
Type of chronic disease & & \\
- Diabetes Mellitus & 30 & 30.9 \\
- Hypertension & 33 & 34.0 \\
- Heart diseases & 4 & 4.1 \\
- Others & 30 & 30.9 \\
- Family history of asthma & 10 & 9.5 \\
- Smoker in the family & 101 & 96.2 \\
\hline
\end{tabular}

Table 4: Distribution of the Study Sample Regarding Their Risk Factors of Bronchial Asthma Disease ( $\mathrm{N}=105)$

\begin{tabular}{llllll}
\hline Risk factors & Yes & & No \\
& & No. & $\%$ & No. & $\%$ \\
\hline - & Caused by common cold & 105 & 100.0 & 0.0 & 0.0 \\
- & Exposed to dust & 105 & 100.0 & 0.0 & 0.0 \\
- & Exposed to smoking & 105 & 100.0 & 0.0 & 0.0 \\
- & Exposed to heavy effort & 101 & 96.2 & 4 & 3.8 \\
- & Eating specific meals & 28 & 26.7 & 77 & 73.3 \\
- & Dressing specific clothes & 24 & 22.9 & 81 & 77.1 \\
- & Smell bad odor & 40 & 38.1 & 65 & 61.9 \\
- & Increased with cold whether & 105 & 100.0 & 0.0 & 0.0 \\
- & Increased with anxiety & 105 & 100.0 & 0.0 & 0.0 \\
- & Dealing with animals & 91 & 86.7 & 14 & 13.3 \\
- & Rearing at home birds & 91 & 86.7 & 14 & 13.3 \\
- & Exposure to sun lights & 105 & 100.0 & 0 & 0.0 \\
- & Present kitchen at home & 25 & 23.8 & 80 & 76.2 \\
- & Present original heater & 93 & 88.6 & 12 & 11.4 \\
- & Exposure to pollutions & 8 & 7.6 & 97 & 92.4 \\
- & Dust floors & 72 & 68.6 & 33 & 31.4 \\
- & Suffering from skin rash & 24 & 22.9 & 81 & 77.1 \\
- & Suffering from bronchitis & 95 & 90.5 & 10 & 9.5 \\
- & Suffering from nose allergy & 32 & 30.5 & 73 & 69.5 \\
\hline
\end{tabular}

Table 5: Distribution of the Study Sample Regarding Their Quality of Life QOL $(\mathrm{N}=105)$

\begin{tabular}{clll}
\hline \multicolumn{2}{l}{ QOL Score } & Range & Mean + SD \\
\hline$\bullet$ & Symptoms score & $32.2-90.6$ & $70.6+16.6$ \\
- & Activity score & $86.5-100$ & $95.2+5.1$ \\
- & Impacts score & $78.5-99.4$ & $89.3+4.9$ \\
- & Total score & $77.1-95.3$ & $87.9+5.4$ \\
\hline
\end{tabular}


As regards sex, more than half of the study sample was males, while about less than half were females. The females had poor QOL. This finding is consistent with Lu \& Chang, 1998 supported that elderly females have lower life satisfaction than males. Other studies have found similar gender differences in the health-related quality of life of asthmatics. Belloch et al. found that women showed a poorer HRQoL than men, as well as higher degrees of anxiety and depression. Osborne et al. reported poorer quality of life in female asthmatics as assessed by some of the dimensions. In another study by Temprano and Manino supported that women demonstrated worse asthma control compared with men with regard to several short-term and long-term measures, despite reporting higher rates of inhaled corticosteroid use and routine asthma care visits.

According to Clark 2000 reported that better QOL overall was observed among men more than women and men scored significantly higher in the emotional contribution perception of illness, suggesting that men tolerate chronic illness without being emotionally affected to the same extent as women. Also this result was supported by Ibrahim M., 2005, who explained the findings of this study in which the elderly men had better QOL than the elderly women.

Concerning marital status in the present study, about two thirds of the studied sample was widows, about one third was married and very small percent were single. The impact of widowhood with its many losses as loss of companionship and intimacy was found to be most profound among women than men as most widowed women may have a feeling of loss of prestige, because of their dependence on their husbands. This is agree with Alonson, 2004 and Kobau, et al., 2004 reported that the unmarried or widow had low scores of QOL, Batty 2004 revealed that married elders tend to have better QOL than the widowed through the emotional and instrument support of the spouse. Unmarried women have the lowest score regarding loneliness and depression so they developed a supportive network of friends and relatives.

Regarding the educational level, the majority of the studied sample was illiterate, about one tenth could read and write. It was observed that the illiterate patient had low QOL score than the educated patient. These findings are supported by those of Knurowshi, et al., 2004, who reported that the better QOL among elderly with high level of education.

Also the present study agrees with Alonson et al., 2004 reported that low level of education had been associated with poor QOL. It was mentioned in many literatures that higher education among the elders can properly identify and aware of the important role of social support and realizing the need of increasing contact with mates, family member and friends in order to achieve a highly satisfied life. Increasingly, Melzer 2001 stated that better educated elders can exhibit a more coping mechanisms with many stressful situations during their life. The elders with higher educational level reflect higher overall quality of life. Since the highly educated had more knowledge and ability to scope with the pressures and problems in life, they could have better control and arrange their own lives, they scored higher on quality of life than the less educated (Tseng \& Wang, 2001).

Concerning the occupational status, almost half of the studied sample was house wife, while more than one third of them were retired, and about more than one fifth of them were worked. In the present study the worked patients had higher QOL satisfaction than not worked patients, because elderly people with employment before retirement were paid and saving, permitting them to be more autonomous financially, thus enjoying a better QOL. This is in agreement with Koltyn \& Brill 2003 who added that whatever the elders' occupational status, most elders are faced with loss of chances for managing their previous abilities, hobbies, and interests that occupied most of their previous years.

According to Ford, 2005 who founded that asthma had a major negative impact on the health related quality of life in the community and that its impact was similar to that of other chronic health conditions, this similar to the present study who founded that there is statistical significant difference between time of severity and total score range P-value 0.00 . Also this study agree with Breeze et al., 2004 who reported that asthma results in significant impairment of HRQOL which correlates poorly with the spirometric measurement.

\section{Conclusion}

Based on the results of the present study, it can be concluded that: Risk factor of asthma has a significant effect on elderly QOL (symptoms score, activity, impacts and total scores).There is lack of awareness regarding asthma (risk factors, complications, management, and prevention of its recurrence).

\section{Recommendations}

Based on the results of the present study, the following recommendations are suggested:

1) Increasing elderly awareness about the importance of regular chest assessment for early detection, management, and prevent complications of asthma.

2) Presence of gerontological nurses in out-patients clinics to increase awareness regarding normal physiological changes associated with aging process and needs of geriatrics to activate role in health promotion and disease prevention.

3) The mass media should used more effectively to improve awareness of elderly about asthma (risk factors, complications, management and prevention of its recurrence).

\section{References}

[1] Adams (2004): Psychological factors and asthma quality of life: a population based study, Thorax PP; 59: 930-935 doi: $10.1136 /$ thx. 010256

[2] Alonson J., Ferrer M., Gande CB., \& Ware G., (2004): Health related quality of life associated with chronic condition in eight countries: results from the international quality of life assessment (IQOLA) project Qual life Res, PP. 13(2): 283-98.

[3] Batty D. (2004): Older People Face a Lonely Future, Think Tank Warns. J Gerontol Nurs; 30 (6): 401-22.

[4] Belloch A., Perpina M., Martinez-Moragon E., Alfredo A., MartinezFrances M., (2003): Gender differences in health-related quality of life among patients with asthma. J Asthma; 40: 945-53.15. https://doi.org/10.1081/jas-120024595.

[5] Braman, S.S. (2006): The global burden of asthma. Chest, 130(1 Suppl): 4-12S. https://doi.org/10.1378/chest.130.1_suppl.4S.

[6] Breeze E, Jones D, Fletcher E. (2004): Association of Quality of Life in Old Age in Britain with Socioeconomic Position: Baseline Data from a Randomized Controlled Trail. J Epidemiol and Community Health; 58 (8): 667-73. https://doi.org/10.1136/jech.2003.014035.

[7] Chinn, S., Downs, S. and Anto, M., (2006): Incidence of asthma and net change in symptoms in relation to changes in obesity. Eur Respir J, 28, pp. https://doi.org/10.1183/09031936.06.00150505

[8] Clark J. G., (2000): Uses and abuses of hearing loss classification. Asha, 23, Pp: 493-500.

[9] Debajyoti B., Madhu S., Barthwal, Chandan K., and Vardhan V., (2011): Asthma in the Elderly, Medicine Update-2011, PP; 389-392.

[10] Ford S., (2005): The epidemiology of obesity and asthma, J Allergy Clin Immunol, 115, pp. 897-909 [quiz 910] Article. https://doi.org/10.1016/j.jaci.2004.11.050.

[11] Geriatrics \& Gerontology International, (2006): Elderly Quality of life Volume 6, Issue 3, pages 149-158, September.Available at http://onlinelibrary.wiley.com/journal/10.1111/ (ISSN) 1447 0594/issues.

[12] Gibson P., McDonald M., and Marks B., (2010): Asthma in older adults. Lancet; Asthmatics: results of the ECRHS II study." Allergy 376: 803-13.

[13] Ibrahim M. (2005): Quality of Life of Institutionalized Elders. Alexandria: University of Alexandria, Faculty of Nursing.

[14] Joyce E., Jill A., Manuel P, James A., Cyril M., Cary E., Pharm D., and Harrison V., (2010): Asthma Guidelines for Clinical Care. PhDUMHS Asthma Guideline, March 2010. 
[15] Knurowski T., Lazic D., \& Vandijk P., (2004): Survey of the health status and quality of life of elderly in Poland and croatia. Croat Med J. PP.45 (6):750-6.

[16] Kobau R., Safran MA., Zack MM., Moriartyo G., (2004): Sad, blue, or depressed day, health behaviors and health related quality of life, health quality life outcomes, PP. 2 (1):40-2.

[17] Koltyn F. \& Brill A. (2003): The Association between Physical Activity and Quality of Life in Older Women. Women's Health Issues; 11 (2): 471-80.

[18] Lu \& Chang, (1998): Age-adjusted rates of death by asthma a review of research literature and Appl Psychophysiol Biofeedback. Journal of medicine Science, P. 139-149.

[19] Melzer D, Leveille G, \& Guralnik M. (2001): Educational Differences in the Prevalence of Mood and Personality Disorders in old Age. The Journals of Gerontology Series B: Psychological Sciences and Social Sciences; 56(3):294-301. https://doi.org/10.1093/geronb/56.5.S294.

[20] Osborne L., Vollmer M., Linton P., \& Buist S., 1998: Characteristics of patients with asthma within a large HMO. Am J Respir Crit Care Med; PP.157:123-8.

[21] Pascual RM, Johnson JJ, and Peters SP. (2008): Asthma: clinical presentation and management. In: Fishman AP, Elias JA, Fishman JA, Grippi MA, Senior RM, Pack AI, editors. Fishman's pulmonary diseases and disorders. 4th ed. New York: McGraw Hill; 815.

[22] Quadrelli A., Roncoroni A., King-Kallimanis L., Oort J, Nolte S, Schwartz E., and Sprangers G. (2011): Features of asthma in the elderly. Using structural equation modeling to detect response shift in performance and health-related quality of life scores of multiple sclerosis patients. J Asthma. Qual Life Res.; 20: 1527-40. https://doi.org/10.1007/s11136-010-9844-9.

[23] Stein, K., Jacobsen, P., Blanchard, C., \& Thors, C., (2004): Further validation of the Multidimensional Fatigue Symptoms InventoryShort Form (MFSI-SF). Journal of Pain and Symptoms Management, 27, 14-23. https://doi.org/10.1016/j.jpainsymman.2003.06.003

[24] Temprano J., \& Mannino D., (2009): The effect of sex on asthma control from the National Asthma Survey.J Allergy Clin Immun; P. 23: 854-60.17. https://doi.org/10.1016/j.jaci.2008.12.009.

[25] Tseng S., \&Wang R., (2001): Quality of Life and Related Factors among Elderly Nursing Home Residents in Southern Taiwan. Public Health Nurs; 18 (5): 304-11. https://doi.org/10.1046/j.15251446.2001.00304.x.

[26] Turner, Eastwood P., Cook A., \& Jenkins S., (2011): Improvements in symptoms and quality of life following exercise training in older adults with moderate/severe persistent asthma Respiration; 81(4):302-10.doi: 10.1159/000315142. Epub 2011 May 22. https://doi.org/10.1159/000315142. 